TID-4500, UC-25

Metals, Ceramics, and Materials

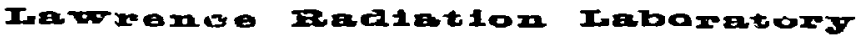 \\ UHIVESITY OF CALIFORHIA \\ IIYER YORE
}

UCRL-50901

\section{DYNAMIC YIELD STRENGTHS \\ OF LIGHT ARMOR MATERIALS}

W. H. Gust

E. B. Royce

\begin{abstract}
LEGAL NOTICE
This teport was prepared as an sceount of work sponsored by the United States Government. Meikher the United States nor the United States Atomic Entergy

Cammission, nor any of their employees, nor aily of theif contractors, subcontractors, or their employees, makes any warranty, express or implied, or assumes any' legal liability or responsibility for the accuracy, pleteness or usefulness of any information, apparatus, groduct or process disclosed, or represents that its use would not infringe privately owned rights.
\end{abstract}




\section{Contents}

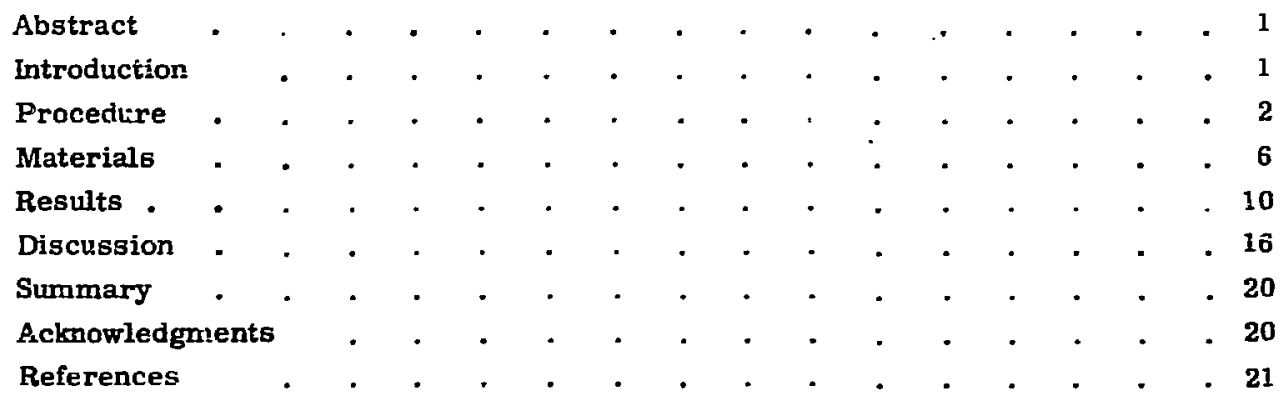




\title{
DYNAMIC YIELD STRENGTHS OF LIGHT ARMOR MATERIALS
}

\begin{abstract}
Inclined mirrors and prisms have been used to determine Hugoniot elastic limits (HEL's) for the light ceramics $\mathrm{B}_{4} \mathrm{C}, \mathrm{BeO}$, four 6 rades of $\mathrm{Al}_{2} \mathrm{O}_{3}, \mathrm{SiC}, \mathrm{TiB}_{2}, \mathrm{AlB}_{12}$, $\mathrm{TiBe}_{12}, \mathrm{Be}_{2} \mathrm{~B}$, and $\mathrm{ZrBe}_{13} ;\langle 100\rangle,\langle 110\rangle$, and $\langle 111\rangle \mathrm{Si}$; and a maraging steel, Vascomax 350. Hugoniot parameters to about 1 Mbar were measured for $\mathrm{B}_{4} \mathrm{C}$, $\mathrm{BeO}$, and the four aluminas, and to about

0.5 Mbar for Si. Four-wave shock structures were observed for $\langle 110\rangle$ and $\langle 111\rangle \mathrm{Si}$. These have been related to the HEL's and to two successive phase transitions. In Vascomax 350, a three-wave structure was seen which appears to be related to the 130-kbar transition in Fe. Three-wave structures were also observed in $\langle 100\rangle \mathrm{Si}$ and $\mathrm{AlB}_{12}$.
\end{abstract}

\section{Introduction}

The study of the physical phenomena associated with ballistic penetration has been aided by a series of m-asurements of the dynamic compressive yield strengths or Hugoniot elastic limits (HEL's) for a number of high-strength materials, particularly cerainics. * Knowledge of the dynamic response of potential armor materials to shock loading was the primary objective, but since there was a dearth of information concerning response of armor ceramics in the deformational regime, the measurements were, in some instances, extended to higher pressure levels - on the order of 1 Mbar. Material response was observed as driving pressure and shock propagation distance were varied, and the dependense of shock propagation characteristics on porosity and inpurity cortent were noted. Of more fundamental interest, the response of single crystals to shock loading along different axes was recorded.

A Hugoniot elastic limit is measured through the resolution of the two-wave shock structure which is usually formed

This Frork was performed as part of the LRL Light Armor Program, initiated by the Advanced Research Projects Agency (ARPA); some preliminary results were reported in the following documents: Mark Wilkins, Charles Honodel, and David Sawle, An Approach to the Study of Light Armor, Lawrence Radiation Laboratory, Livermore, Rept. UCRL-50284 (1967). Mark L. Wilkins, Second Progress Report of Light Armor Program (U), Lawrence Radiation Laboratory, Livermore, Rept. UCRL-50349 (I967) (CDI). Mark L. Wilkins, Third Progress Report of Light Armor Program, Lawrence Radiation Laboratory, Livermore, Rept. UCRL-50460 (1968). M. L. Wilkins, C. F. Cline, and C. A. Honodel, Fourth Progress Report of Light Armor Program, Lawrence Radiation Laboratory, Lirermore, Rept. UCRL50694 (1969). 
by the elastic and the more slowly propagating deformational wave. Widespread application of the techniques involved is relatively new; well over half of the existing data on Hugoniot elastic limits is less than five years old.

The hydrostatic compression of $\mathrm{Al}_{2} \mathrm{O}_{3}$ has been measured by Bridgman ${ }^{1}$ and by Hart and Drickamer, ${ }^{2}$ and the hydrostatic compression of BeO by Weir and Shastis ${ }^{3}$ and Cline and Stephens. ${ }^{4}$ Sonic velucities have been measured under hydrostatic pressure on $\mathrm{Al}_{2} \mathrm{O}_{3}{ }^{5-7}$ and on $\mathrm{BeO} .^{8}$ Single-shock compression data at high pressures have been reported for $\mathrm{Al}_{2} \mathrm{O}_{3}$ by McQueen and Marsh, ${ }^{9}$ and similar work by Hori on $\mathrm{geO}$ has been reported by Cline and Stephens. Two-wave measuraments on $\mathrm{Al}_{2} \mathrm{O}_{3}$ have been made by 5 rook and Graham 10 and by Ahrens, Gust, and Royce. $^{11}$
Hydrostatic high-pressure measurements of the resistivity of srystalline silicon have been reported by Minomura and Drickamer ${ }^{12}$ and $x$-ray diffraction experiments at high pressure were reported by Wentorf and Kasper ${ }^{13}$ and by Jamieson. ${ }^{14}$ McQueen ${ }^{15}$ reported measurements of the Hugoniot elastic limit for Si made by Wackerle, while $\mathrm{Al}^{\prime}$ tshuler $^{16}$ and Pavlovskii ${ }^{17}$ reported similar resuits.

Here we report information ${ }^{18}$ on the Hugoniot elastic limits, shock compression parameiters, and elastic properties for polycrystalline forms of $\mathrm{B}_{4} \mathrm{C}, \mathrm{BeO}$, four grades of $\mathrm{Al}_{2} \mathrm{O}_{3}, \mathrm{SiC}, \mathrm{TiB}_{2}, \mathrm{AlB}_{12}$, $\mathrm{TiBe}_{12}, \mathrm{Be}_{2} \mathrm{~B}$, and $\mathrm{ZrBe}_{13}$. Fisults from shccks propagated along the $\langle 100\rangle,\langle 110\rangle$, and $\langle 111\rangle$ axes of crystalline silicon and the compressional characteristics of a maraging steel are also recorded.

\section{Procedure}

Explosive systems were used to generate shocks which resulted in ceramic pressures ranging from about 180 to 1000 kbar for this series of experiments. Data at pressures greater than 500 kbar were obtained through the use of the flash-gap technique. ${ }^{19}$ Experiments at pressures below 500 kbar were done with either inclined mirrors ${ }^{20}$ or inclined prisms, 21 the latter being the more sensitive of the two techniques.

The geometry used in the inclined mirror experiments is shown in Fig. 1. It has the advantage of simultaneously providing continuous direci measurement of the free-surface velocity of the base plate and of the two samples as well as shock velocity through the two samples. For most experirrents, two mirrors were used to ohtain the state of the base plate, which was of 2024 aluminum, while the other two provided separate measurtments on two samples of material. In most experiments, the two samples were of identical material. The angles of inclination were $3^{\circ}$ or $5^{\circ}$ for the base-plate mirrors, and $1.5^{\circ}$ and $3^{\circ}$ for the mirrors on the samples.

The mirrors are intensely illuminated with a high-explosive-driven argon light source, and the reflected image is viewed with a rotating-mirror streaking camera, as shown schematically in Fig. I. The initial shock causes the iree surface to move across the wedge-shaped gap at 


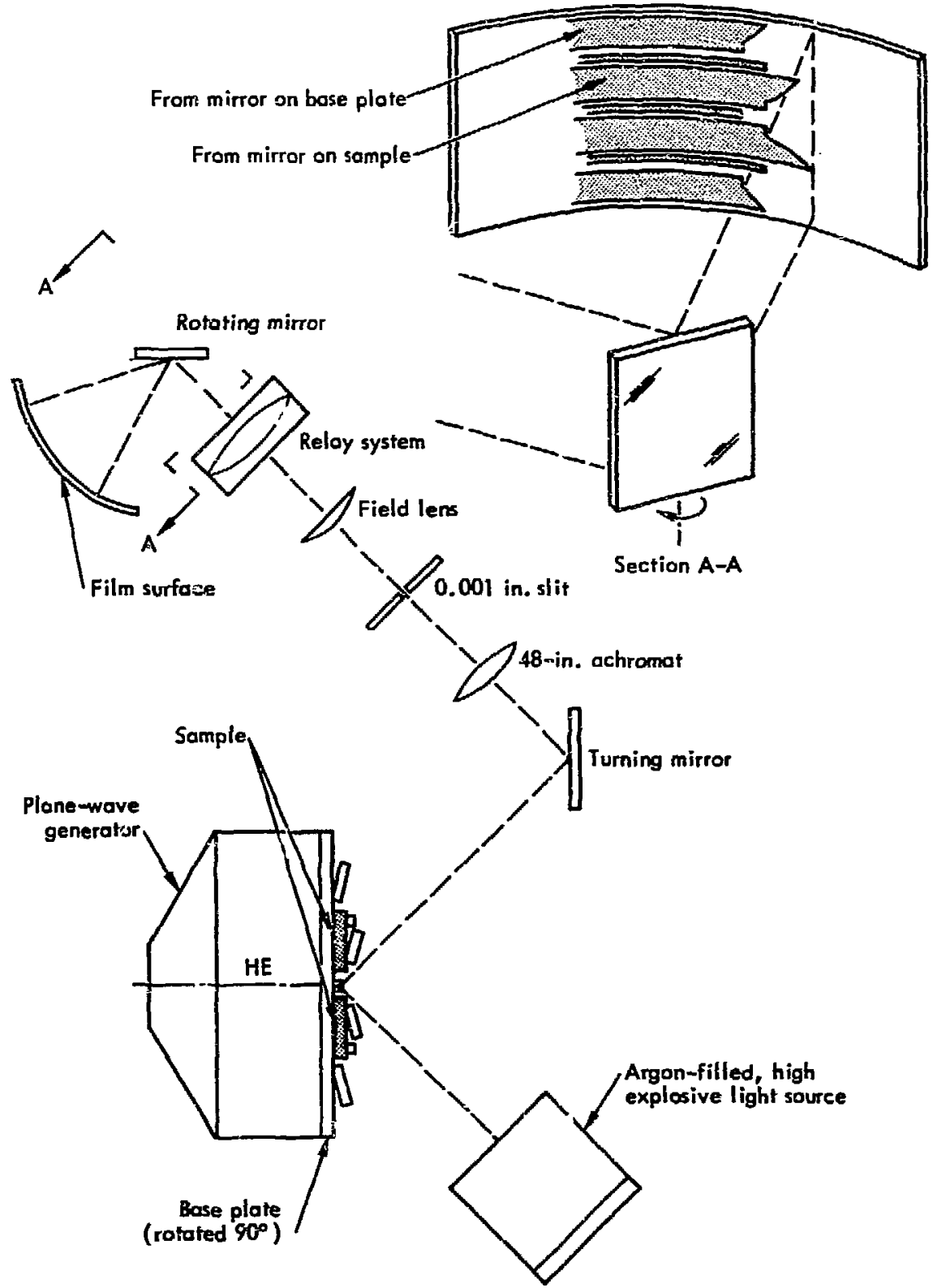

Fig. 1. Experimental geometry for inclined-mirror experiments. The inclined mirrors are silvered on the side next to the samples, are illuminated with an explosively driven argon light source, and are viewevi inrough a small slit in a rotating-mirror streaking camera.

velocity $U_{f_{1}}$, where it progressively contacts the mirror surface along the in- clined length. Reflection along the mirror is then progressively destroyed by 
the moving impact point so that the light is progressively cut off. The velocity of the light-dark discontinuity is proportional to the material free-surface velocity, and, when viewed through a small slit, the discontinuity is recorded as a slope on the streaiing camera record. A subsequent wave moving with velocity $U_{s_{2}}+U_{p_{1}}$ (where $U_{S}$ is the shock velocity and $U_{p}$ the particle velocityl overtakes the boundary moving at $\mathrm{U}_{\mathrm{fs}_{1}}$ and a different, faster contact rate occurs; this rate results in a different slope, which is related to $U_{f_{2}}$, the velocity at which the free surface now moves. A similar procedure may be applied to any additional waves.

An experimental record and the preshot mirror array are shown in Fig. 2. The traces show examples of the film clit-oif angles which are related to loss of reflectivity caused by the elastic and deformational waves. The Hugoniot parameters are related to the records through the relations

$$
U_{s_{1}}=\frac{x_{1}-x_{0}}{t_{1}-t_{0}}=\frac{H W}{t_{1}}
$$

and

$$
\mathrm{U}_{\mathrm{fs}_{1}}=\frac{\mathrm{W} \tan Q}{\mathrm{M} \tan \gamma},
$$

where $\mathrm{H}$ is the sample thickness, $\mathrm{Z}_{1}$ the flat mirror cut-off position on the film record, $W$ the camera streaking rate, $M$ the magnification factor which relates the film record to actual experiment dimensions, $\alpha$ the angle of mirror inclination, and $y$ the angle between the free surface film trace and the normal to the camera sweep, as shown in Fig. 1. Small corrections are applied to account for deviations from ideal geometry.

In these experiments the particle velocity associated with the elastic shock was

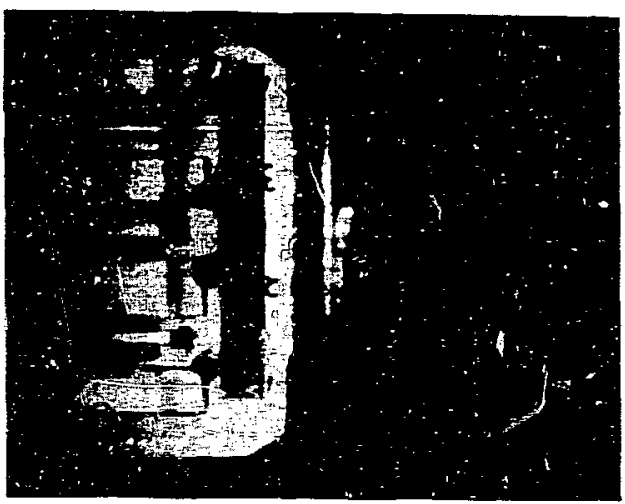

Iig. 2. Typical record from an inclinedmirror experiment on $\mathrm{B}_{4} \mathrm{C}$ ceramic at 430 kbar. At the left is a setup picture of th? experiment, taken with the camera slit removed. For trie shot record, time progresses from left to right, the important part of the record being the light cutoff at the right-hand side.

obtained from the free-surface approximation, $\mathrm{U}_{\mathrm{p}_{1}}=\mathrm{U}_{\mathrm{fs}_{1}} / 2$. This implies that the entropy increase related to the elastic shock state is small, and that material properties in the initial and elastic shock states are substantially the same. The shock stress and volume corresponding to the elastic limit are then obtained through use of the Hugoniot conservation relations (in laboratory coordinates), namely,

$$
\sigma_{1}=\rho_{0} \mathrm{U}_{\mathrm{s}_{\mathrm{i}}} \mathrm{J}_{\mathrm{P}_{1}}
$$

and

$$
\left(v_{1} / v_{0}\right)=1-\left(u_{p_{1}} / u_{s_{1}}\right)
$$

Figure 3 displays an $x$-vursus- $t$ representation of the wave reflections which result from the interaction of the elastic wave with the free surface. It his been found that $\mathrm{U}_{\mathbf{s}_{2}}$ is relatively insensitive to the values used for $U_{s_{1}}^{\prime}$ and $U_{s_{2}}^{\prime}$, and it may be assumed that the shock and rarefaction 
processes for the elastic wave are nearly reversible. Hence, good approximations $\operatorname{are} \mathrm{U}_{\mathrm{s}_{1}}^{t}=\mathrm{U}_{\mathrm{S}_{1}}-\mathrm{U}_{\mathrm{p}_{1}}$ and $\mathrm{U}_{\mathrm{s}_{2}}^{\prime}=\mathrm{U}_{\mathrm{s}_{1}}+$ $U_{\mathrm{fs}_{1}}$. The apparent second shock velocity is given by

$$
\begin{aligned}
U_{s_{2}} & =\frac{x_{2}-x_{0}}{t_{2}-t_{0}} \\
& =\frac{x_{1}-x_{0}+\left(t_{2}-t_{1}\right) U_{f s_{1}}}{t_{2}-t_{0}} \\
& =\frac{H+U_{f_{1}}\left\langle t_{2}-t_{1}\right\rangle}{t_{2}-t_{0}} .
\end{aligned}
$$

It may then be sihown $n^{11}$ that the true second shock velocity is given by where

$$
\rho_{1}=\rho_{0}\left(\frac{U_{s_{1}}}{\bar{U}_{s_{1}}-U_{p_{1}}}\right)
$$

When two-wave shock structures were neasured, the deformational particle velocity, $\mathrm{U}_{\mathrm{P}_{2}}$, was determined by the irrpedance matching technique. ${ }^{22}$ For this technique, the state of the aluminum base plat was determired from free-sul iace velocity measurements made during each experiment. Particle velacity was also determined by use of the free-surface velocity approxination, $\mathrm{U}_{\mathrm{p}_{2}}=\mathrm{U}_{\mathrm{fs}_{2}} / 2$. Precisions of the shock and particle veloc-

$U_{s_{2}}=\frac{U_{s_{1}}^{\prime} \bar{U}_{s_{2}}\left(U_{s_{1}}-U_{f s_{1}}\right)+U_{s_{1}} U_{s_{2}}^{\prime}\left(\bar{U}_{s_{2}}-U_{f s_{2}}\right)-U_{s_{1}}^{\prime} U_{s_{2}}^{\prime}\left(U_{s_{1}}-\bar{U}_{s_{2}}\right)}{U_{s_{2}}^{\prime}\left(U_{s_{1}}-U_{f s_{1}}\right)+U_{s_{1}}^{\prime}\left(\bar{U}_{s_{2}}-U_{f_{s_{1}}}\right)-U_{f s_{1}}\left(U_{s_{1}}-\bar{U}_{s_{2}}\right)}$.

The final stress for a two-wave shock is obtained from

$\sigma_{2}=\sigma_{1}+\rho_{1}\left(U_{s_{2}}-U_{p_{1}}\right)\left(U_{p_{2}}-U_{P_{1}}\right)$,

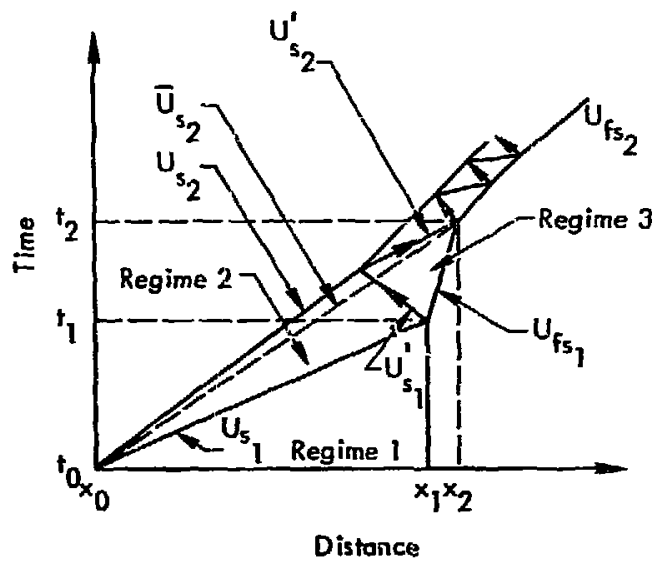

Fig. 3. Schematic representation of two waves in the ceramic sample and their interaction with the free surface. ity measurements for the deformational shock front are usually better than $\pm 1 \%$ and $\pm 3 \%$, respectively. Uncertainty in the determination of particle velccity for the elastic shock is usually about $5 \%$, although in a few experiments the mirrors were not in contact with the samples and the resulting gap caused gross error in the measurement for the elastic wave. In some instances the recorded film trace cutoff was curved, and the cutoff angle was taken to be the initial slope ot the curve.

The inclined prism technique is similar to the inclined mirror technique in application. The difference is that reflection from the mirrors is from a metallized surface, while the prisms operate on total internal reflection, associated with the difference in the indexes of refraction of the glass and vacuum. The loss of rellectivity of the mirrors is caused by the destruction of the reflecting surface on impact, while 
for the prisms the loss of reflectivity is caused by a drastic change of the index of refraction of the medium outside the prism as the sample free surface moves into full contact. As the shot is set up, the prism contacts the sample surface at unly a few points.

Materials subject to shock-induced phase transitions may exhibii. shock structures with more than two waves. In this instance, the elastic wave is identified by the equivalence of $\mathrm{U}_{S_{1}}$ with $C_{L}$, the ultrasonicaliy determined longitudinal sound speed at 1 bar, and any remaining waves are related to either phase transitions or the final state achieved in the particular experiment. In experiments on Vascomax 350 , three-wave shock structures were observed. Shocks that propagated along the $\langle 110\rangle$ and $\langle 111\rangle$ axes of the crystalline silicon exhibited four-wave structures. A detailed analysis of the interactions of a three- or four-wave shock structure is beyond the scope of this report; hence, no corrections are made on velocities of second, third, or fourth shocks. In other words, the data reduction procedure uses apparent or average values for the shcak velocities. The more complex waves are then evaluated through an extension of the equations,

$$
\begin{aligned}
& U_{s_{n}}=\frac{H+\sum_{1}^{I} \frac{U_{i s_{n-1}}\left(s_{n}-t_{n-1}\right)}{t_{n}-t_{0}},}{U_{f s_{n}}}=\frac{W \tan \alpha}{M \tan \gamma_{n}}, \\
& U_{p_{n}}=\frac{u_{f s_{n}}}{2} .
\end{aligned}
$$

Here $Z$ (Eg. (1)) is either the flat rrirror cutoff position on the film record or the point of intersection of the extrapuiation for each of the successive free-surface velocity slopes.

Application of the conservation of mass and momentum across the shock front leads to the Hugoniot equations which, for multiple wave structures, may be expressed in terms of stress and volume as

$$
\begin{gathered}
\sigma_{n}=v_{n-1}^{-1}\left(U_{s_{n}}-U_{p_{n-1}}\right)\left(U_{p_{n}}-U_{p_{n-1}}\right) \\
v_{n}=v_{n-1}\left(U_{n-1}-U_{p_{n}}\right) /\left(U_{s_{n}}-U_{p_{n-1}}\right)
\end{gathered}
$$

\section{Materials}

The hot-pressed polycrystalline $\mathrm{B}_{4} \mathrm{C}$ was fabricated by the Norton Company of Worcester, Massachusetts." Cheraical and spectrochemical analyses supplied by

\footnotetext{
Reference to a company or product name does not imply approval or recommendation of the product by the University of California or the U.S. Atomic Energy Commission to the exclusion of others that may be suitable.
}

the manufacturer showed a B-to-C ratio of 3.93:1 and $\mathrm{B}+\mathrm{C}=93.12 \%$. The major impurities are listed in Table 1. The structure is rhombohedral with a $=5.63 \AA$, $c=12.14 \AA .23$ Theoretical density of the conglomerate was about $2.52 \mathrm{~g} / \mathrm{cc}$; 2ctual density was about $2.50 \mathrm{~g} / \mathrm{cc}$.

The BeO studied war a commercially available polycrystalline material, 
Táble 1. Impurities in ceramics studied (in wt\%).

\begin{tabular}{|c|c|c|c|c|c|c|}
\hline Impurity & $\mathrm{B}_{4} \mathrm{C}$ & $\mathrm{BeO}$ & $\begin{array}{l}\mathrm{Al}_{2} \mathrm{O}_{3} \\
\mathrm{AD}-85\end{array}$ & $\begin{array}{c}\mathrm{Al}_{2} \mathrm{O}_{3} \\
\mathrm{P}-3142-1\end{array}$ & $\begin{array}{l}\mathrm{Al}_{2} \mathrm{O}_{3} \\
\mathrm{Al}-995\end{array}$ & $\begin{array}{c}\mathrm{Al}_{2} \mathrm{O}_{3} \\
\text { Hot pressed }\end{array}$ \\
\hline B & & & & & & $<0.02$ \\
\hline $\mathrm{Si}$ & & 0.22 & 7.0 & & 0.2 & 0.3 \\
\hline as $\mathrm{SiO}_{2}$ & 0.08 & 0.46 & 15.0 & $\sim 2.0$ & 0.4 & 0.6 \\
\hline $\mathrm{Ca}$ & & & 1.5 & & 0.03 & 0.02 \\
\hline as $\mathrm{CaO}$ & 0.1 & & 2.1 & $\sim 0.5$ & 0.04 & 0.03 \\
\hline $\mathbf{M g}$ & & 0.09 & 2.0 & & 0.3 & 0.2 \\
\hline as $\mathrm{MgO}$ & 0.02 & 0.16 & 3.3 & $\sim 0.5$ & 0.5 & 0.3 \\
\hline $\mathrm{Ba}$ & & & 0.8 & & & \\
\hline as $\mathrm{BaO}$ & & & 0.9 & & & \\
\hline $\mathbf{F e}$ & & 0.01 & 0.3 & 0.02 & 0.07 & 0.03 \\
\hline as $\mathrm{Fe}_{2} \mathrm{O}_{3}$ & & 0.014 & 0.4 & 0.03 & 0.1 & 0.04 \\
\hline \multicolumn{7}{|l|}{$\mathrm{V}$} \\
\hline as $\mathrm{V}_{2} \mathrm{O}_{3}$ & & & & & 0.01 & \\
\hline$\Gamma \mathbf{i}$ & & & 0.2 & & 0.01 & \\
\hline as $\mathrm{TiO}_{2}$ & & & 0.3 & & 0.015 & \\
\hline \multicolumn{7}{|l|}{$\mathbf{N i}$} \\
\hline as $\mathrm{NiO}$ & $0.01-0.05$ & & & & & \\
\hline $\mathrm{Cr}$ & & & & 0.5 & & \\
\hline as $\mathrm{Cr}_{2} \mathrm{O}_{3}$ & & & & 0.8 & & \\
\hline $\mathrm{Na}$ & & 0.01 & 0.05 & & & 0.3 \\
\hline as $\mathrm{Na}_{2} \mathrm{O}$ & & 0.02 & 0.07 & & & 0.4 \\
\hline $\mathrm{Ga}$ & & & & & & 0.02 \\
\hline $\mathrm{Al}_{2} \mathrm{O}_{3}$ & $0.1 \sim 0.5$ & & & & & \\
\hline Source & Mfr. & Mfr. & LRL & LRL & LRL & Mfr. \\
\hline
\end{tabular}

designated as Thermalox-995 by Brush Beryllium Company, Elmira, Ohio.

This ceramic has a nominal BeO content of $99.5 \%$. Major impurities are listed in Table 1. The structure of crystalline $\mathrm{BeO}$ is the hexagonal wurtrite structure with $a=2.70 \AA, c=4.40 \AA$. Theoretical density of the material was about $3.01 \mathrm{~g} / \mathrm{cc}$; actual density was $2.84 \mathrm{~g} / \mathrm{cc}$.

Four grades of alumina, which varied considerably in porosity and impurity content, rere studied. These includer Coors AD-85 manufactured by Coors
Porcelain Company, Golder, Colorado; Diamonite P-3142-I from Diamonite Products Company, Shreve, Ohio; a high-purity grade fabricated by a hotpressing technique by the Carborundum Company, Niagra Falls, New York; and data taken from Ref. 11 for Wesgo-995, produced by the Western Gold and Platinum Company, Belmont, California.

Table 1 lists impurities present in amounts greater than $0.01 \%$. Aluminat is hexagonal, with $a=4.758 \AA, c=$ $12.925 \AA$ A. 23 
Table 2. Hugoniot parameters.

\begin{tabular}{|c|c|c|c|c|c|c|c|c|c|c|c|c|c|c|c|c|}
\hline & \multirow[b]{2}{*}{$\mathrm{B}_{4} \mathrm{C}$} & \multirow[b]{2}{*}{ BLO } & \multicolumn{4}{|c|}{$\mathrm{Al}_{2} \mathrm{O}_{3}$} & \multirow[b]{2}{*}{$\mathrm{sic}$} & \multirow[b]{2}{*}{$\mathrm{TiH}_{2}$} & \multirow[b]{2}{*}{$\mathrm{MH}_{12}$} & \multirow[b]{2}{*}{ Titses } & \multirow[b]{2}{*}{$\mathrm{b}_{2} \mathrm{x}$} & \multirow[b]{2}{*}{$\therefore \mathrm{rH}$} & \multicolumn{3}{|c|}{ silican } & \multirow[b]{2}{*}{ 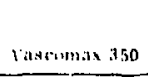 } \\
\hline & & & $\begin{array}{l}\text { Ilot } \\
\text { presaed }\end{array}$ & Al-1005 & $p-31+2-1$ & $A B-B 5$ & & & & & & & $1100 !$ & $(1,0)$ & (111) & \\
\hline Density, $\rho_{0}\left(g / \mathrm{cn}^{3}\right)$ & 2.50 & 2,84 & 11,02 & 3.131 & 3.72 & 3.42 & $3,0 ! 3$ & +.516 & 2.54 & 2.2114 & $1,9 !+1$ & 2.734 & 2.330 & & & 8,1911 \\
\hline Theo density (g/am) & $2.52^{\mathrm{a}}$ & $3,01^{n}$ & $3.00^{\mathrm{a}}$ & 3.973 & a.: $1^{a}$ & $3.613^{\mathrm{3}}$ & $3.11-3.0^{4}$ & $4,6,3^{b}$ & $2.6-2.7^{6}$ & $2.28^{12}$ & $3.4^{12}$ & $2.724^{\mathrm{B}}$ & & & & \\
\hline Void rractlon & 0.020 & 0,056 & 0.008 & 0,040 & $0.05,5$ & D.orili & & $-0,02$ & $-0.02 \cdot 0,016$ & -0 & -0.17 & 0 & & & & \\
\hline \multicolumn{17}{|l|}{ Ultrasonic tnod Mll ${ }^{c}$ (Mtbar) } \\
\hline L.ongitudinal, L & 4.75 & 3.713 & 4.40 & 4.07 & 3.71 & 8.07 & 3. .31 & 3,72 & 3,67 & 3.04 & 2.1111 & 2.144 & $1.41^{r}$ & \multirow{3}{*}{$\begin{array}{r}.1914 \\
10.74 \\
0.30\end{array}$} & \multirow{3}{*}{$\begin{array}{l}3.0 .1 \\
0.01\end{array}$} & וזי \\
\hline Shear, o & 1,132 & 1.43 & $1.41 !$ & 1.47 & (.2!) & 0.1111 & 1.6 .1 & 3.34 & 1.6i: & 1.27 & 1.24 & $1.2 n$ & 0.110 & & & $01.71 \mathrm{~s}$ \\
\hline Bulk, $B^{d}$ & 2.32 & 1.888 & 2.10 & 2.11 & 1,99 & 1,50 & 1.70 & 2.511 & $1.11 !$ & 1.7 .11 & 1.83 & 1,22 & $1,1311^{\mathrm{n}}$ & & & 1.72 \\
\hline${ }_{\text {HEL }}{ }^{B}$ & 104 & 02 & 134 & $1: 3$ & $m a$ & 61 & $10: 3$ & $" 1$ & $32^{4}$ & 54 & $n 5^{0}$ & $71^{2}$ & 112 & $3 x$ & 54 & 411 \\
\hline$\Delta_{0} \cdot \frac{2}{3} Y_{0},\left(\frac{L-B}{L}\right)_{0}{ }_{H E L}{ }^{r}$ & 70 & \$1 & 42 & 40 & +1 & 27 & ti & +4 & 2.201 & $30^{\prime \prime}$ & $17^{\circ}$ & $+2^{\prime \prime}$ & 30 & 20 & 311 & ill \\
\hline \multicolumn{17}{|l|}{ Huguriat rit } \\
\hline $\begin{array}{l}A_{1} \text { (Milbar) } \\
A_{2}{ }^{h} \text { (Mbar) }\end{array}$ & $\begin{array}{l}1,11 \\
3,2\end{array}$ & $0.7 \mathrm{~s}$ & $\begin{array}{l}2.2 f i \\
5.8\end{array}$ & 1.t. & 0.5 & 0 & $1.6 \quad 1,3.5$ & 2.45 & $\begin{array}{l}1.7^{4,4} \\
0^{0,1}\end{array}$ & $1 ., 15$ & $1.1^{2}$ & $1.2^{2}$ & 1.1 .31 & $1.1 \mathrm{~s}^{3+1}$ & & 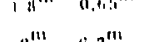 \\
\hline $\mathrm{P}_{\text {min }}{ }^{\mathrm{i}}$ or $\mathrm{P}_{\text {mens }} \mathrm{k}$ (Mbar) & 0.2 & 0.15 & 0.2 & 0.2 & 0.2 & 0.15 & $0.10 .25 !$ & 0.14 & $-0,1^{\mathrm{c}}$ & & $-0.1^{*}$ & $-0.2^{\circ}$ & $0.0 g^{11}$ & $0.095,4$ & & $0.4^{m 11}$ \\
\hline$P_{\max } 1$ (Muar) & 1.0 & 0.0 & 1.2 & 1.2 & 1.0 & 10 & $0.4 \quad 1.01$ & 0.45 & & & $-0.2^{4}$ & & $0.2^{13}$ & $0.7^{11.9}$ & & $0.14^{m 1} \quad 1.6^{\prime \prime \prime}$ \\
\hline
\end{tabular}

${ }^{i} P_{\text {min }}$ and $P_{\text {max }}$ deftine range of datis und valldity af tie fit. 
Impurity analyses for the other materials listed in Table 2 were not availa'ile. Stärting powders of the highest purity obtainable were stated to have been used in their manufacture; they were about $97 \%$ pure. The sources of these materials are given in Table 3 .

Table 3. Hugoniot elastic limits.

\begin{tabular}{|c|c|c|c|c|}
\hline Material & Manufacturer & $\begin{array}{l}\text { Density } \\
\left(\mathrm{g} / \mathrm{cm}^{3}\right)\end{array}$ & $\begin{array}{l}\text { Sample } \\
\text { chickness } \\
\text { (mm) }\end{array}$ & $\underset{\text { (kbar) }}{\text { HEL }}$ \\
\hline $\mathrm{B}_{4} \mathrm{C}$ & Norton Co., hot pressed & 2.50 & $\begin{array}{l}3.2 \\
5.8 \\
7.2 \\
9.6\end{array}$ & $\begin{array}{l}162 \pm 9 \\
158 \pm 4 \\
149 \pm 20 \\
137 \pm 4\end{array}$ \\
\hline $\mathrm{BeO}$ & $\begin{array}{l}\text { Brush Beryllium Co., } \\
\text { Thermalox } 995\end{array}$ & 2.84 & $\begin{array}{r}3.2 \\
6.4 \\
8.9 \\
12.8\end{array}$ & $\begin{array}{l}91 \pm 11 \\
82 \pm 10 \\
73 \pm 10 \\
74\end{array}$ \\
\hline $\mathrm{Al}_{2} \mathrm{O}_{3}$ & $\begin{array}{l}\text { General Electric Co.. } \\
\text { Lucalox (Ref. 11) }\end{array}$ & 3.97 & $\begin{array}{r}6.4 \\
12.7\end{array}$ & $\begin{array}{l}112 \pm 2 \\
111 \pm 12\end{array}$ \\
\hline $\mathrm{Al}_{2} \mathrm{O}_{3}$ & $\begin{array}{l}\text { Carborundum Co., hot } \\
\text { pressed }\end{array}$ & 3.92 & $\begin{array}{r}3.2 \\
6.0 \\
9.6 \\
12.8\end{array}$ & $\begin{array}{r}160 \pm 6 \\
134 \pm 5 \\
112 \pm 3 \\
92 \pm 3\end{array}$ \\
\hline $\mathrm{Al}_{2} \mathrm{O}_{3}$ & $\begin{array}{l}\text { Wostern Gold and Platinum } \\
\text { Co.Al-955 }\end{array}$ & 3.81 & 6.4 & $83 \pm 5$ \\
\hline $\mathrm{Al}_{2} \mathrm{O}_{3}$ & Diamonite P-3142-1 & 3.72 & $\begin{array}{l}3.2 \\
4.1 \\
8.0 \\
9.0\end{array}$ & $\begin{array}{l}79 \pm 5 \\
95 \pm 2 \\
81 \pm 4 \\
72\end{array}$ \\
\hline $\mathrm{Al}_{2} \mathrm{O}_{3}$ & Coors Porcelain Co., AD-85 & 3.42 & $\begin{array}{l}3.2 \\
6.3 \\
9.6\end{array}$ & $\begin{array}{l}65 \\
61 \pm 5 \\
61\end{array}$ \\
\hline $\mathrm{SiC}$ & Carborundum Co., Type KT & 3.09 & 6.4 & $91 \pm 15$ \\
\hline $\mathrm{TiB}_{2}$ & Union Carbide & 4.52 & 6.4 & $81 \pm 35$ \\
\hline $\mathrm{AlB}_{12}$ & LRL Powder from CERAC & 2.54 & 6.4 & 32 \\
\hline $\mathrm{TiBe}_{12}$ & Brush Beryllium Co. & 2.28 & 6.4 & 53 \\
\hline $\mathrm{Be}_{2} \mathrm{~B}$ & LRL Powder from CERAC & 1.99 & 6.4 & 65 \\
\hline $\begin{array}{l}\mathrm{ZrBe}_{13} \\
\left(2 \% \mathrm{Zr}_{2} \mathrm{Be}_{17}\right)\end{array}$ & Brush Beryllium Co. & 2.73 & 6.4 & $71 \pm 11$ \\
\hline$\langle 100\rangle \mathrm{Si}$ & Ventron Elestronics Corp. & 2.330 & 6.4 & $92 \pm 10$ \\
\hline$\langle 110\rangle \mathrm{Si}$ & Ventron Electronics Corp. & 2.330 & 6.4 & $53 \pm 6$ \\
\hline$\langle 111\rangle \mathbf{S i}$ & Ventron Electronics Corp. & 2.330 & 6.4 & $54 \pm 3$ \\
\hline Vascomax 350 & Vanadium Pacific Steel Co. & 8.08 & 6.4 & 48 \\
\hline
\end{tabular}


Vascornax 350 is a maraging steel; the composition is $\mathrm{Fe}, 11.8^{\%}{ }_{9} \mathrm{Co}, 18.1^{\circ}{ }_{0}^{\circ} \mathrm{Ni}$, $4.7 \%$ Mo, $1.36 \%$ Ti. It is manufactured by the Vanadium-Pacifjr Steei Company, Miaywood, California.

Oriented single crystals of silicon were obtained from the Ventron Electronics Corporation, Bradford, Pennsylvania.

Theoreticai and actual densities for the ceramics are listed in Table 2. Theoretical densities were calculated under the assumption that the impurities were all present as discrete crystals of the oxide. Probably some of the impurities formed silicates or aluminates, but this should not crange the density much as long as the impurity is not present in large amounts. The AD-85 alumina ceramic was the most impure material studied; and the theoretical density of this material was calculated as $3.66 \mathrm{~g} / \mathrm{cc}$. (The density of crystalline alumina is 3.985.) R. Landingham of LRL measured the density of crushed AD-85 with a helium picnometer. For a powder of grain size less than $37 \mu$, he measured a density of $3.635 \pm 0.02 \mathrm{~g} / \mathrm{sc}$. Such a measurement is a lower limit on the theoretical dersity of the ceramic, whose bulk density is $3.42 \mathrm{~g} / \mathrm{cc}$, and this lends scre confidence to the method used to calculate theoretical densities.

Longitudinal and shear sonic velocities were measured oni eaçh sample used is order to eliminate gross variations in properties between samples. These measurements, made by H. L. Dunegan and P. L. Knauss of LRL, were stated to be accurate within about $2 \%$; sonic velocity scatter between samples was about $\pm 2 \%$ from the average. Blastic moduli calculated from the average velocities obtained are listed in Table 2.

\section{Results}

Table 4. Axial yield strengths and phase-transition pressures.

\begin{tabular}{|c|c|c|c|c|c|c|}
\hline Material & $\underset{\text { (kbar) }}{\text { HEL }}$ & $\begin{array}{l}\text { Volume } \\
\left(\mathrm{cm}^{3} / \mathrm{g}\right)\end{array}$ & $\begin{array}{c}\text { First } \\
\text { transition } \\
\text { stress } \\
\text { (kbar) }\end{array}$ & $\begin{array}{l}\text { Volyume } \\
\left(\mathrm{cm}^{3} / \mathrm{g}\right)\end{array}$ & $\begin{array}{l}\text { Second } \\
\text { transition } \\
\text { stress } \\
\text { (kbar) }\end{array}$ & $\begin{array}{l}\text { Volume } \\
\left(\mathrm{cm}^{3} / \mathrm{g}\right)\end{array}$ \\
\hline$\langle 100\rangle \mathrm{Si}^{\mathrm{a}}$ & $92 \pm 10$ & 0.406 & \multicolumn{2}{|c|}{ None observed } & $140 \pm 4$ & 0.385 \\
\hline$\langle 110\rangle \mathrm{Si}$ & $53 \pm 6$ & 0.418 & $102 \pm 6$ & 0.399 & $131 \pm 3$ & 0.384 \\
\hline$\langle 111\rangle \mathrm{Si}$ & $54 \pm 3$ & 0.418 & $101 \pm 3$ & 0.400 & $137 \pm 5$ & 0.380 \\
\hline $\begin{array}{c}\text { Vascomax } \\
350^{b}\end{array}$ & $48 \pm 20$ & 0.122 & $180 \pm 3$ & 0.115 & - & - \\
\hline
\end{tabular}

$a_{\text {tritial volume }}=0.429 \mathrm{~cm}^{3} / \mathrm{g}$.

$b_{\text {Initial volume }}=0.134 \mathrm{~cm}^{3} / \mathrm{g}$.

Values of the stress at the HEL, the dynamic yield strength, and values of the stresses where phase tzansitions were seen are listed in Tables 2,3 , and 4 .
Hugoniot Data for the entire series of experiments is summarized in Figs, 4 through 10, and fits to the Hugoniot data are given in Table 2 . 
If strain rates are negligible and equilibrium is achieved, the notion of a singlevalued HEL is valid. In nonequilibrium cases, as exemplified by shock attenuation with prupagation distance, it should be noted that the form of the driving pulse, which may be an artifact of the HE system and not zquare, may influence the value obtained for the HEL. In these cases the film trace of the free-surface cutoff may be rounded as shown in Fig. 11. Similar rounding may also be associated with dispersion as the elastic wave moves through the material. Where such rounding was observed, $\tan \gamma$ was taken from the initial slope of the rounded trace. This usually resulted in a larger value for $\tan \gamma$ and consequently a smaller free-surface velocity than would be obtained from the straightline slopes associated with the square-wave pressure pulses. Despite the uncertainty caused by lack of equilibrium and nonsquare

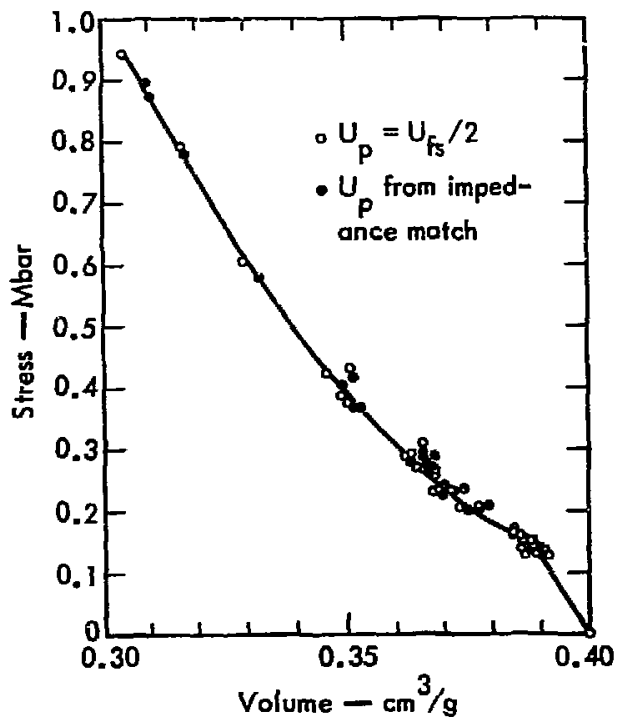

Fig. 4. Experimental Hugoniot for $\mathrm{B}_{4} \mathrm{C}$ ceramic.

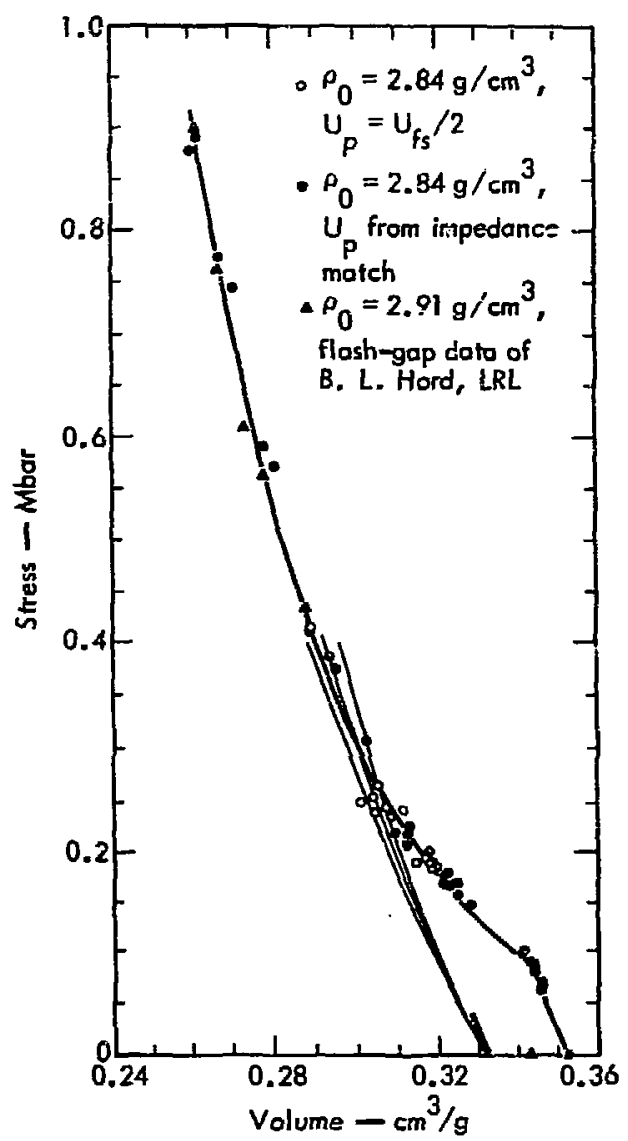

Fig. 5. Experinental Hugoniot for BeO ceramic. The light lines represent the range of uncertainty in the ultrasonically determined isotropic compression curve. The short heavy line is from the static compression work of Cline and Stephens (Ref. 4).

driving pulses, characteristic values for the HEL's have been assigned, but obviously these should be used with caution.

In the flash-gap measurements, $\mathrm{U}_{S}$ was less than $C_{L}$. This is consistent with earlier calculations ${ }^{11}$ that indicated that the free-surface movement associated with the elastic wave was not sufficient to cause the gap to flash before the second wave 


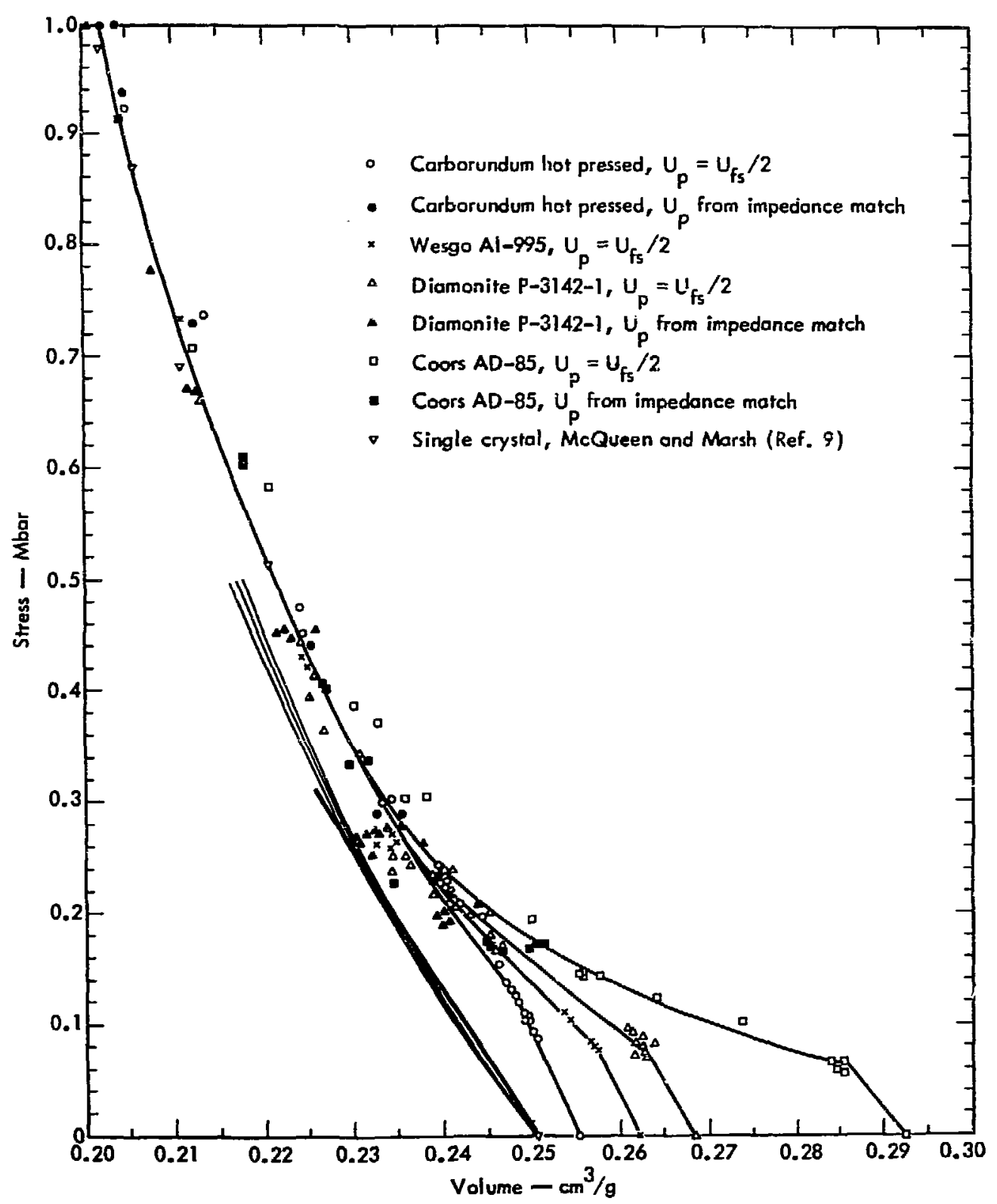

Fig. 6. Experimental Hugoniots for. $\mathrm{Al}_{2} \mathrm{O}_{3}$ ceramics. The light lines represent the range of uncertainty in the ultrasonically determined isotropic compression curve. The heavy lini s from the static compression work of Hari and Drickamer (Ref. 2).

arrived at the bourdary. Hence, the recorded flash-gap data are related to the second wave. In some instances where $C_{L}$ was greater than $U_{5}$, the analysis was 


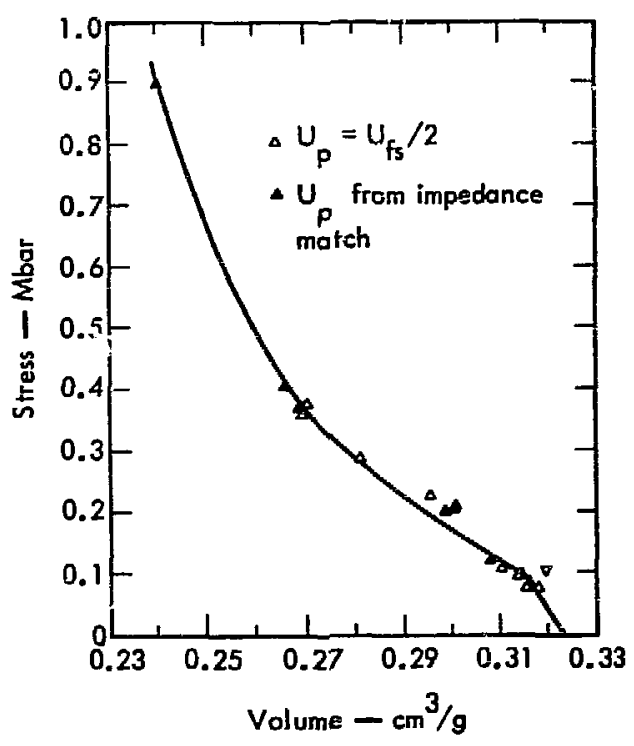

Fig. 7. Experimental Hugoniot for SiC eeramic.

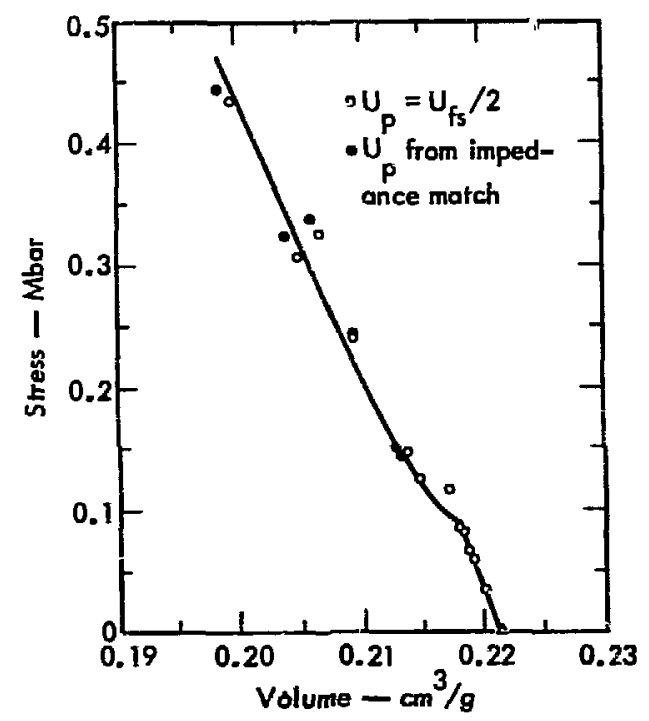

Fig. 8. Experimental Hugoniot for $\mathbf{T i B}_{2}$ ceramic.

made more exact by assuming average values for the elastic wave parameters and then applying two-wave data reduction

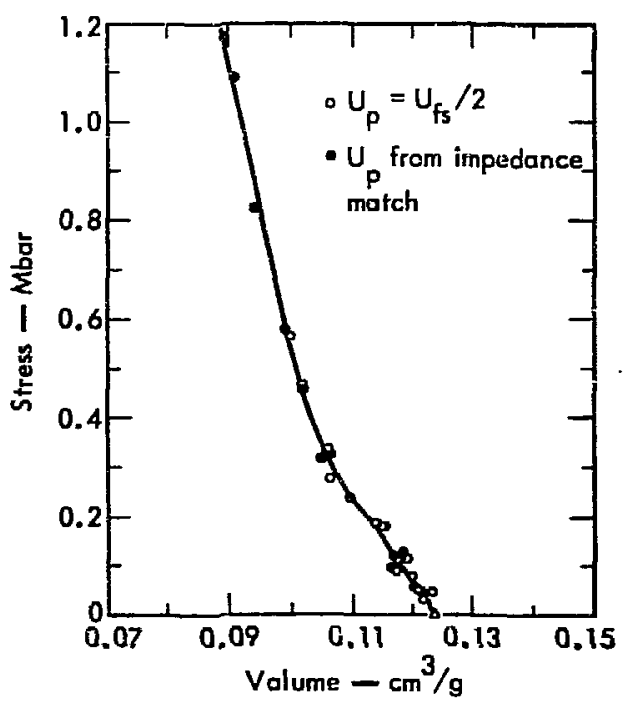

Fig. 9. Experimental Hugoniot for Vascomax 350 .

methods. Where $U_{\mathbf{s}}$ is only slightly smaller than $C_{L}$, the two-wave treatment offered no improvement.

HEL's were obtained for all the materials studied. In all cases multiple wave structures were observed, the leading wave propagating at near $C_{L}$. The HEL's listed for $\mathrm{B}_{4} \mathrm{C}$ are the highest recorded for any polycrystalline material. 24 The HEL for Vascomax 350 is about twice as high as for any iron alloy previously measured. $^{24}$ For the aluminas, the HEL's do not vary continuously with density. Impurity content or material processing seems to be important. Observation of the variation of HEL amplitude with sample thickness or shock propagation distance discloses possible precursor shock attenuation for $\mathrm{B}_{4} \mathrm{C}$ and hot-pressed $\mathrm{Al}_{2} \mathrm{O}_{3}$. However, variation in amplitude for given thicknesses was comparable to the apparent attenuation. The other materials exhibited no consistent trend. No major variation of 


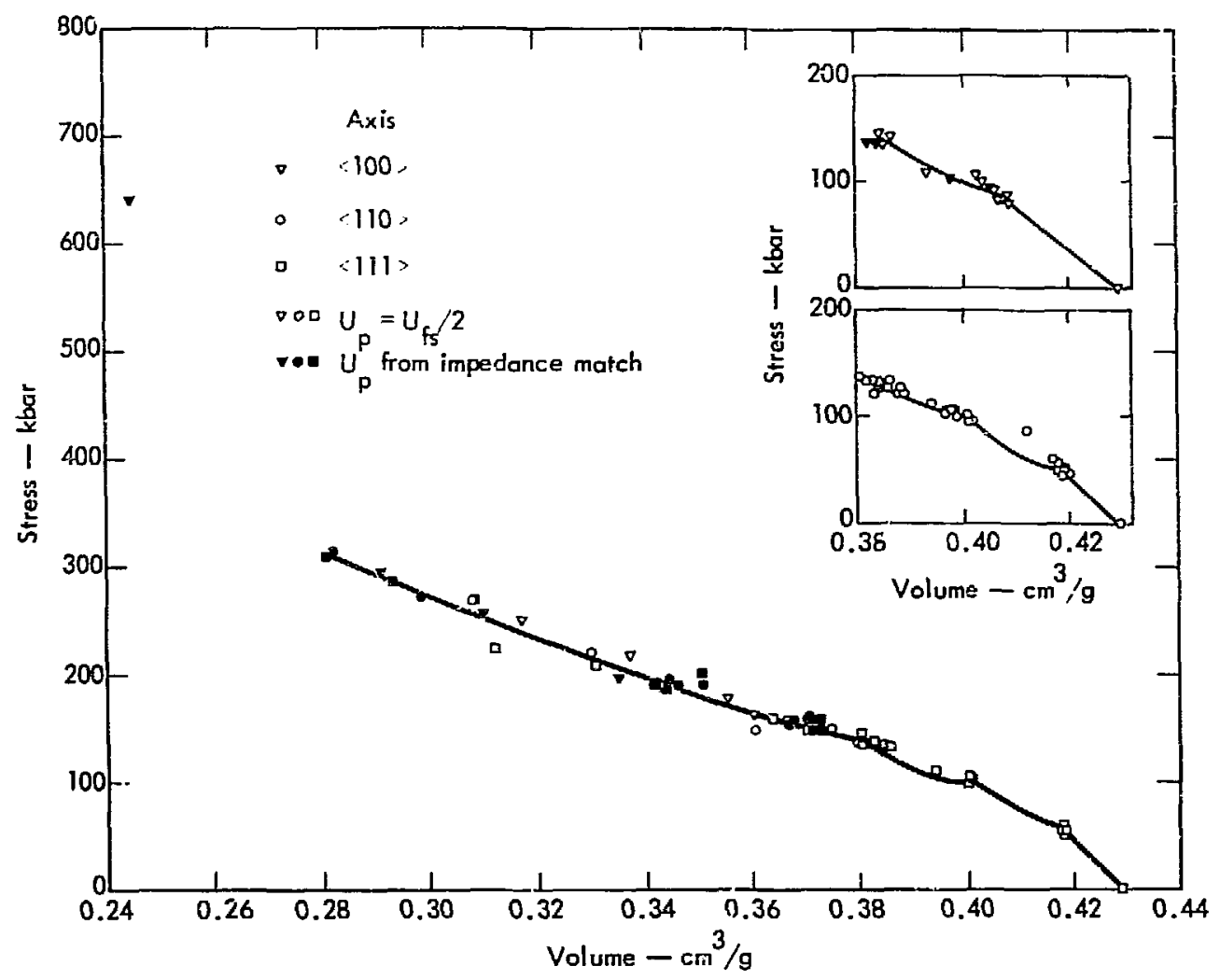

Fig. 10. Experimental Hugoniot for crystalline silicon.

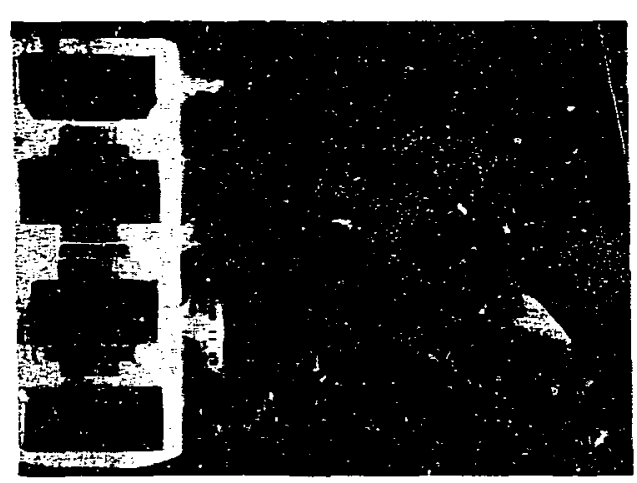

Fig. 11. Streaking-camera film record from an inclined-mirror experiment on Diamonite $\mathrm{Al}_{2} \mathrm{O}_{3}$ p-3142-1, showing a curved film trace from a ramp-shaped wave, 200 kbar.
HEL amplitude with driving pressure was observed.

For the more porous materials, BeO and Diamonite and Coors $\mathrm{Al}_{2} \mathrm{O}_{3}$, it was noted that in the compaction regime, i.e., from the yield point to about $300 \mathrm{kbar}$, the value obtained for $U_{p_{2}}$ from impedance matching was consistently greater than $\mathrm{U}_{\mathrm{fs}} / 2$. This is the opposite of results obtained for metals and is consistent with a model in which the porosity is permanently crushed out of the material by the shock compaction.

Figure 6 indicates that, within the limits of uncertainty involved, the four grades of $\mathrm{Al}_{2} \mathrm{O}_{3}$ converge to a Hugoniot which agrees 
well with single crystal data obtained by McQueen and Marsh. 9

In developing a representation of these Hugoniot results, as given in Table 2, a simple model was used. In this model. the crushing behavior of the porous materials is ignnred, and the materials are assumed to behave according to an elastic, perfecily plastic model. In this case, one may obtain the pressure on compression by simply subt:acting the quantity $\Delta \sigma$ from the measured longitudinal stress on compression, $\sigma$. Simple elasticity shows that

$$
\Delta a=2 Y_{0} / 3=(L-B) \sigma_{H E L} / L \text {, }
$$

where $Y_{0}$ is the yield stress under uniaxial stress, $\sigma_{H E L}$ is the stress at the Hugoniat elastic limit, and $L$ and $B$ are the longitudinal and bulk moduli, respectively.

The resulting $P-V$ curve is then fitted with the polynomial

$$
P=A_{1} \mu+A_{2} \mu^{2}+A_{3} \mu^{3},
$$

where

$$
\mu=\left(V_{0}-V\right) / V .
$$

Since the temperature rise on the shock compression of these materials is small, ${ }^{11}$ the omission of the energy term in the equation of state has no serious consequences, as long as it is used only for shock-wave problems. While this model provides an adequate description of the behavior of these materials under compression, it may not be adequate to describe their release behavior and should be used with caution.

The ceramics $\mathrm{B}_{4} \mathrm{C}, \mathrm{BeO}$, and $\mathrm{Al}_{2} \mathrm{O}_{3}$ all have Hugoniots represented by a quadratic $(P-\mu)$ polynismial, i.e., $A_{3}=0$ in Eq. (10). For the more porous ceramics, $A_{I}$ is significantly less than the elastic bulk modulus, showing that the material is crushing up in the pressure range of a few hundred kilobars. A large value for $A_{2}$ in these cases results from the curvature of the Hugoniot associated with the completion of crushing. At pressures below 500 kbar. the data scatter somewhat more than abovs, probably reflecting some nonrepeatability in the process of crushing up.

$\mathrm{TiB}_{2}$ appears to behave in a similar way, except that the data do not extend to sufficiently bigh pressures to accurately determine the value of $A_{2}$. The data for SiC, on the other hand, are represented by a constant ratio $P / \mu\left(A_{2}=A_{3}=0\right)$ below 400 kbar, but above that pressure the Eugoniot appears to stiffer markedly. The full range of the data is only roughly represented by the second fit given.

For $\mathrm{AlB}_{12}, \mathrm{TiBe}_{12}, \mathrm{Be}_{2} \mathrm{~B}$, and $\mathrm{ZrBe}_{13}$, only two shots were fired on each material. For this reason, the Hugoniot above the HEL can only be represented by a constant ratio $\mathrm{P} / \mu$. $\mathrm{AlB}_{12}$ exhibited a possible multiple wave structure, indicating a phase transition at 62 kbar (the quality of the record precludes a positive assignment). This transition is ignored in making the fit.

In crystalline silicon, two successive phase transitions were observed above the HEL. The pressures for these transitions varied with crystal orientation; they are given in Table 4. Surprisingly, the iit with $A_{3} \neq 0$, which ignores the phase transitions, is a good representation of the data for all the orientations. The volume compression associated with the various transitions is taken up in the negative value of $A_{2}$.

The maraging steel Vascomax 350 shows a much larger effect of a phase transition 
at 180 kbar. Accordingly, two fits are given. Presumably the transition is the bec $-h \cdot p$ transition cbserved in pure iron at 130 kbar.

\section{Discussion}

It has been noted ${ }^{11,25}$ that the Hugoniots for alumina and quartz are offset from the isotropic or hydrostatic compression curve, whereas for $\mathrm{MgO}$, the Hugoniot and isotropic compression curve are essentially coincident. This offset has been interpreted as the result of anisotropic stress in the deformational state, since only the stress component in the shock propagation direction is measured. Thus, a comparison of the Hugoniot with an isotropic compression curve will yield information on the stress anisotropy behind the shock front.

The temperature rise on the shock compression of the ceramics studied is so small ${ }^{1}$ that there is no need to distinguish between isothermal, isentropic, and shock compression. Hence, sonic measurements of the compressibility can be used to produce an isotropic compression curve. We take this compression curve in the Murnaghan form, which requires the normal bulk moduius and its pressure derivative as input parameters: ${ }^{26}$

$$
P=\frac{B_{\text {so }}}{B_{\text {so }}^{\prime}}\left[\left(\frac{v_{0}}{V}\right)^{B_{\text {so }}^{\prime}}-1\right]
$$

This is, of course, based on the expansion of the bulk modulus in a power series in the pressure and the truncation of the series after the linear term. Anderson ${ }^{26}$ has shown that this form is in agreement with experimental data; the error introduced by the truncation is less than the scatter in his data. $\mathrm{Yu}^{27}$ on the other hand, has attempted to evaluate the next term in the series from Anderson's data.

Since we are going to extend the sonic compression curve to $500 \mathrm{kbar}$, we must have some estimate of the reliability of the data and the equation-of-state form. It may be noted that sonic measurements have been reported by many authors, particularly for $\mathrm{Al}_{2} \mathrm{O}_{3}$. Typically the results reported by various authors differ by amounts significantly greater than the reported precision of the individual measurements. Presumably this is due to variations between the samples used by different authors. For the purposes of this work the various reported results have been averaged, after some subjective attempts to evaluate the individual reports. The RMS deviations between reported results were then taken as estimates of the uncertainty in the averages. Data for both single and polycrystalline samples were used. The quadratic term in the bulk modulus expansion was taken as zero, and $\mathrm{Yu}^{\prime}$ 's estimate of a $5 \%$ pressure contribution at 500 kbar in $\mathrm{Al}_{2} \mathrm{O}_{3}$ was used to estimate the error introduced by the omission of this term. These procedures may be overly pessimistic, but it is difficult to justify any smaller error limits.

Table 2 and Fig. 12 show the density variation of the various moduli for the slightly porous ceramic aluminas studied in this work. Some of the sonic work reported in the literature is also on materials of less than crystal density. These results 


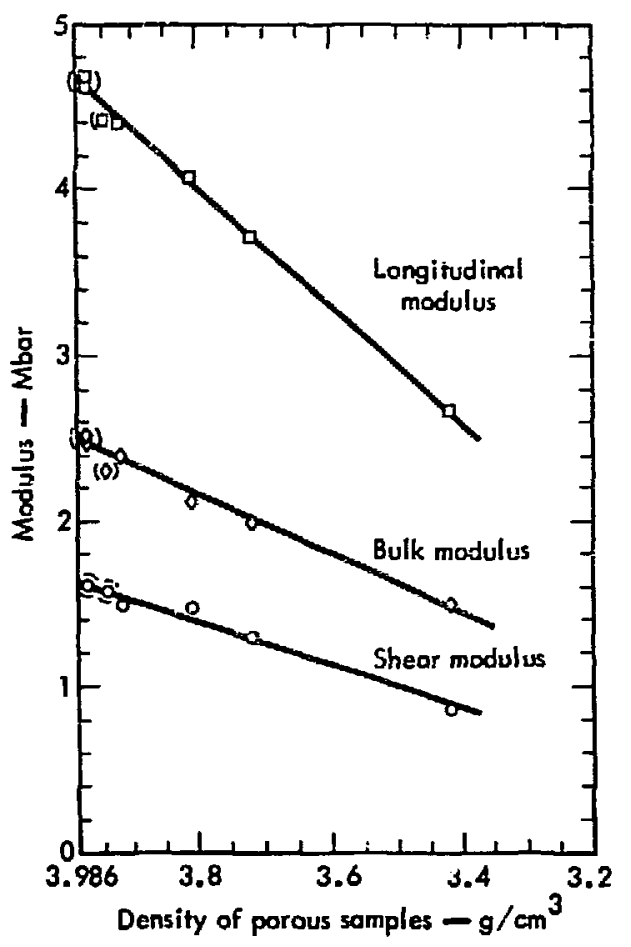

Fig. 12. Longitudinal, bulk and shear moduli versus density for alumina ceramics from ultrasonic measurements.

were corrected to crystal density using the slope from Fig. 12. Table 5 lists the ultrasonic parameters resulting from this analysis of the data in the literature, together with references to the original work. Most important are the estimated accuracies for each parameter. The Murnaghan isotropic compression curves are shown in Figs. 5 and 6 together with the uncer- tainties. The static compression measurements of Hart and Drickamer ${ }^{2}$ and Cline and Stephens ${ }^{4}$ are also shown.

With these isotropic compression curves it is now possible to make some determinations of the yield strengths of the ceramic materials under compression. For this purpose, it is convenient to define a distention ratio $\alpha$, similar to Herrmann's $a:^{33,34}$

$$
\alpha(\sigma)=\mathrm{V}_{\operatorname{Hug}}(\sigma) / \mathrm{V}_{\text {iso }}(\sigma) .
$$

Here $\mathrm{V}_{\text {Hug }}(\sigma)$ and $\mathrm{V}_{\text {iso }}(\sigma)$ are the specific volumes on the Hugoniot and on the isotrcpic compression curve at $\sigma$. The volume for isotropic compression is taken as the volume on the uicrasonic compression curve multiplied by the ratio of the theoretical density given in Table 2 to the theoretical density of the pure material. Thus, the effect of impurities is assumed only to result in a scaling of the density. The compressibility is assumed for the moment to be unaffected by impurities.

Figure 13 shows the values of $\alpha$ obtained at the experimental Hugoniot points versus longitudinal stress up to $500 \mathrm{kbar}$. Each point on the figure is an average of all the shots at that particular driving stress.

If the yield strengih of the material is nonzero under compression, the Hugoniot will be offset from the isotropic compression curve by an amount $\Delta \sigma=(2 \beta) \mathrm{Y}_{0}$, where $Y_{0}$ is the yield strength under

Table 5. Ultrasonic bulk moduli for materials at theoretical density.

\begin{tabular}{llcll}
\hline Material & $\begin{array}{c}\rho_{0} \\
\left(\mathrm{~g} / \mathrm{cm}^{3}\right)\end{array}$ & $\begin{array}{c}\mathrm{B}_{\mathrm{Bo}} \\
(\mathrm{Mbar})\end{array}$ & $\begin{array}{c}\mathrm{B}_{\text {So }}^{\text {s }} \\
\text { (Mbar) }\end{array}$ & \multicolumn{1}{c}{ References } \\
\hline $\mathrm{Al}_{2} \mathrm{O}_{3}$ & 3.986 & $2.51 \pm 1 \%$ & $4.2 \pm 4 \%$ & $5-7,28-30$, this work \\
$\mathrm{BeO}^{3}$ & 3.01 & $2.25 \pm 5 \%$ & $5.5 \pm 20 \% ?$ & $8,30-32$ \\
\hline
\end{tabular}




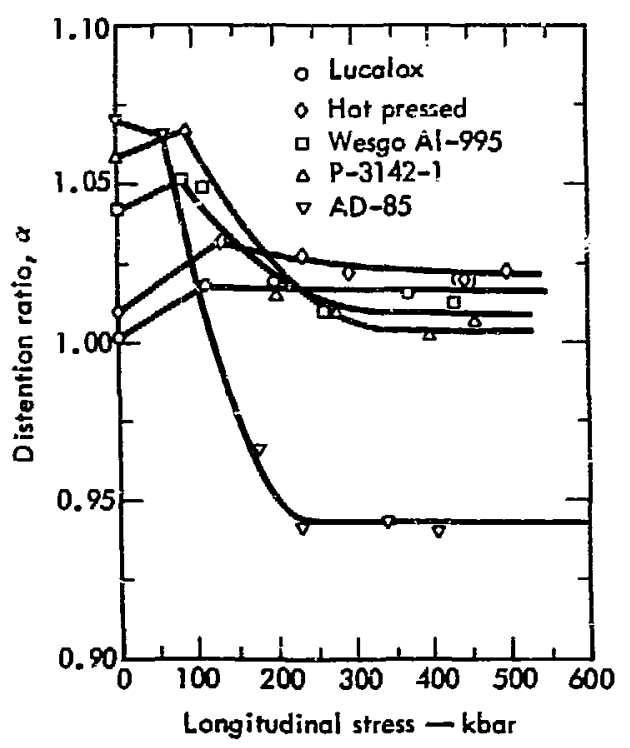

Fig. 13. Distention ratio versus stress for alumina ceramics, $\alpha(\sigma)=$ $\mathrm{V}_{\text {Hug }}(\sigma) / \mathrm{V}_{\text {iso }}(\sigma)$.

uniaxial atress. This stress offset can be represented as a volume offset $\alpha-1=\Delta_{\sigma} / B$, where $B$ is the bulk modulus. Thus, above the yield point, $\alpha$ should be greater than 1 and roughly constant for a nonporous material with a constant yield strength.
The data shown in Fig. $1^{n}$ show this general behavior at pressul :s above the point where the compaction of the porosity of the materials is complete. However, for Diamonite $3142-1, \alpha$ is not as nuch greater than 1 as for the other aluminas, and for Coors AD-85. $\alpha$ is actually less than 1 under ccmpression, indicating a crossing of the isotropic compression curve and Hugoniot. The explanation of this anomaly is found in the presence of $S i$ in these ceramics. Quartz undergoes a polymorphic transition to stishovite on compression. $20,22,35$ This transition is accompanied by a $40 \%$ volume reduction. Other silicates exhibit similar transition. 36 Thus, the presence of the $\mathrm{Si}$ (or $\mathrm{SiO}_{2}$ ) impurity in the Diamonite and Coors aluminas increases the compressibility of these ceramics, and our $\mathrm{Ai}_{2} \mathrm{O}_{3}$ isotropic compression referance curve is not applicable. For the pure alumina ceramics, the limiting vaiue of $\alpha$ is between $1.0 \mathrm{i}$ and 1.02 , corresponding to values of $\Delta \alpha$ between 20 and $40 \mathrm{kbar}$. The exact values are given in Table 6, where the value of the stress offset corresponding to the HEL is also

Table 6. Distention ratios and stress offsets in $\mathrm{BeO}$ and $\mathrm{Al}_{2} \mathrm{O}_{3}$.

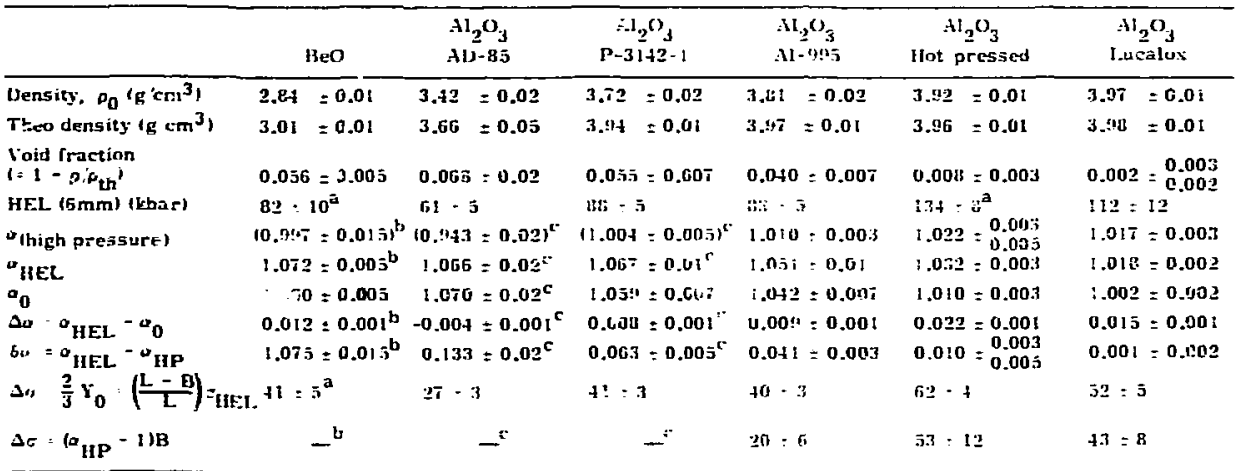

\footnotetext{
${ }^{\mathbf{a}} \mathrm{HEL}$ is th..ckness-dependent; thick somples vield lwwer salur.s.

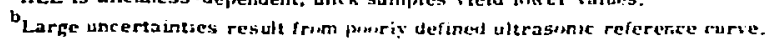

CHaterial convining appreriable si compared apainit reference curve ior pure $\mathrm{Al}_{2} \mathrm{O}_{3}$ corrected for thesretical initial density.
} 
tabulated. The latter was calculated as (L - B) $\sigma_{H E L} / L$, where $L$ is the longitudiral modulus and $B$ the bults modulus from

Table 2. The stress offs et from the highpressure value of $\alpha$ is given by $\left(\alpha_{\mathrm{HP}}-1\right) \mathrm{B}$. It is interesting that for $\mathrm{A}_{2} \mathrm{O}_{3}$, the yierd strength above the HEL decreases somewhat frorn its value at the HEL, but that it is always a least half of the HEL value.

For $\mathrm{BeO}$, on the other hand, the Hugoniot appears to collapse to the isotropic compression curve ahore the FEL. thus indicating a major loss of strength on yielding.

The compaction behavior of porous materials has been of considerable inter est in recent years. $33,34,37-39$ The work most relevant for comparison with this work on ceramics is that on sintered porous metals. 34,39 For these materials, a quadratic variation of $\alpha$ with stress or pressure has been used in the compaction region. $^{33_{j} 34}$ Let $\sigma_{a}$ and $\alpha_{a}\left(=\alpha_{H P}\right)$ represent the stress and vaiue of $\alpha$ at the point where compaction is complete, and $\sigma_{\text {HEL }}$ and $\alpha_{\text {HEL }}$ the values at the HEL. (In Table 6, $\alpha_{0}$ is the value for the uncompressed material.) We can write

$$
\alpha(P)=\alpha_{a}+\frac{\left(\alpha_{\text {HEL }}-\alpha_{a}\right)\left(\sigma_{a}-\sigma\right)^{2}}{\left(\sigma_{a}-\sigma_{\text {HEL }}\right)^{2}} .
$$

Values of $\sigma_{a}$ for the aluminas were estimated from an inspection of Fig. 13 and are close to $4 \sigma_{\text {HEL. The curves drawn in }}$ Fig. 13 are actually this quadratic expression, and the agreement with the experimental data appears to be quite satisfactory.

Four-wave shock structures, as evidenced by four discrete straight-line slopes on the photographic record, were found in experiments in which the shocks were propagated alorg the $\langle 110\rangle$ and $(111\rangle$ axas of crystalline silicon. Close agreement between $U_{S_{1}}$ and $C_{L}$, the ultrasnnically c'etermined longitudinal sourd speed at 1 bar, indicated that the first wave was elastic. The pcssibility of the second wave also being elastic was excluded, since for cubic symmetry the principal propagation directions allowing pure mode fropagation are the $\langle 100\rangle,\langle 110\rangle$, and $\langle 111\rangle$ axes. The second and third waves were therefore taken to be related to two succeeding phase transitions.

In some experiments, the fourth wave was not observed because the observation time allowed by the prism angle of inclination was not long enough. In others, the first phase transition was overdriven so that only three components were seen.

Shocks propagated along the $\langle 100\rangle$ axis showed only three resol; able components: the first was the elastic wave, and the second a phase transition wave which occured at nearly the same $(P, V)$ point as the second phase transition wave for samples of the $\langle 110\rangle$ and $(111\rangle$ orientation. It was noted that in the region of the film record where one might expect a discontinuity related to the first phase transition the record was very fuzzy, thus indicating the possibility of two competing waves with nearly equal shock velocities.

In the $\langle 100\rangle$ direction, the HEL appeared to increase from about 82 to 107 kbar as driving pressure varied from 100 to 360 kbar. This scatter may weil be related to mixing between the HEL and ar unresolved phase transition which should correspond to the 102-kbar transition found for the (110) and (111) axes. If this is assumed, the data could be divided so that the HEL would be abuit 85 kbar, with 
a phase transition at about 100 kbar.

Experiments with thicker samples to allow greater transit-time differences might allow resolution of the two waves.

\section{Summary}

1. Two-wave strurtures in several ceramics are interpreted as resultin from elastic and deformational compression. The Hugoniot elastic limit (HEL), taken as the amplitude of the first wave, then provides a measure of the yield strength of the ceramic.

2. At higher pressures, the yield strength is estimated from the pressure or volume offset between the Hugonict and isotropic compression curve, the latter being estimated from ultrasonic data. For $\mathrm{Al}_{2} \mathrm{O}_{3}$ this yield strength is comparable to but somewhat smaller than the yield strength at the HEL. For BeO the comparison is less clear, but it appears that BeO probaibly loses most of its strength above the HEL. The behavior of $\mathrm{Al}_{2} \mathrm{O}_{3}$ is similar to that of quartz, whereas the behavior of $\mathrm{BeO}$ appears to be similar to MgO.

3. In the regime of partial compaction, a quadratic variation of distention with pressure appears to apply. Material released from such states appears to return to a higher density than its initial density.

\section{Acknowledgments}

It is a pleasure to acknowledge the assistance of M. J. d' Addario, R. D. Breithaupt, W. C. Peterson, W. Simpson, and $W$. H. Stutler for mechanical design and experiment construction. The ex- cellent cooperation recieved at the highexplasive test site was largely due to the efforts of L. J. Bacon, W. C. Mumper, K. F. Humphreys, and B. R. Schliecher. 


\section{References}

1. P. W. Bridgman, Proc. Am. Acad. Arts Sci. 77,187 (1949).

2. M. V. Hart and H. G. Drickamer, J. Chem. Phys. 43, 2265 (1965).

3. C. E. Weir and L. Shastis, J. Am. Ceram. Soc. 39, 319 (1956).

4. C. F. Cline and D. R. Stephens, J. Appl. Phys. 36, 2869 (1965).

5. E. Schreiber and O. L. Anderson, J. Am. Ceram. Soc. 49, 184 (1966).

6. D. H. Chung and G. Simmons, J. Appl. Phys. 39, 5316 (1968), and references therein.

7. J. H. Gieske and G. R. Barsh, Phys. Stat. Sol. 29, 121 (1968).

8. N. Soga, J. Am. Ceram. Soc. 51, 246 (1968) and references therein.

9. R. G. McQueen and S. P. Marsh, Ch. 7 of Handbook of Fhysical Constants,

Revised Edition, S. P. Clark, Jr., Ed. (Geological Society of America, New York, $1966)$.

10. W. P. Brook and R. A. Graham, Bull. Am. Phys, Soc. 11, 414 (1966).

11. T. J. Ahrens, W. H. Gust, and E. B. Royce, J. Appl. Phys. 39, 4610 (1968).

12. S. Minomura and H. G. Drickamer, J. Phys. Chem. Solids 23, 451 (1962).

15. R. H. Wentorf, Jr, and J. S. Kasper, Science 139, 338 (1963).

14. J. C. Jamieson, Science 139, 764 (1963).

15. R. G. McQueen, in Metallurgy at High Pressures and High Temperatures (Gordon and Breach, New York, 1964), P. 80.

16. L. V. Al'tshuler, Soviet Phys. Usp. 8, 82 (1965).

17. M. N. Pavlovskii, Soviet Phys. Solid State, 9, 2514 (1968).

18. Preliminary reports of this work were presented at the meetings of the A.P.S. at Los Alamos, 1968, and Hawaii, 1969. W. H. Gust and E. B. Royce, Bull. Am. Phys. Soc. 13, 901 (1968); W. H. Gust and E. B. Royce, Bull. Am. Phys. Soc. 14, 833 (1969).

19. J. M. Walsh and R. H. Christian, Phys. Rev. 97, 1544 (1955).

20. G. R. Fowles, J. Geoph. Res. 72, 5729 (1967); Stanford Research Institute Report, PLTR 003-61 (1961); D. G. Doran, J. Appl. Phys. 34, 844 (1963).

21. G. Eden and P. W. Wright, in Fourth Symposium on Detonation, ACR-126-ONR (Washington, D. C., 1965), p. 573.

22. Jerry Wackerle, J. Appl. Phys, 33, 922 (1962).

23. A. Taylor, B. J. Kagle, Crystallographic Data on Metal and Alloy Structures (Dover, 1963).

24. O. E. Jones and R. A. Graham, Paper presented at NBS Symposium on Accurate Characterization of the High-Pressure State (1968), to be published; Sandia Laboratories Report SC-R-68-1857 (1968).

25. T. J. Ahrens and R. K. Linde, in Behavior of Dense Media at High Dynamic Pressures (Gordon and Breach, New York, 1968), p. 325. 
26. O. L. Anderson, J. Phys. Chem. Solids 27, 547 (1966); Phys. Earth Planet. Interiors 1,169 (1968).

27. J. S. Yu, Appl. Sci. Res. 19, 220 (1968).

28. N. Soga and O. L. Ande:son, J. Am. Ceram. Soc. 49, 355 (1966).

29. D. H. Chang and W. R. Bussem, J. Appl. Phys. 39, 2777 (1968), and references therein.

30. O. L. Anderson, E. Schreiber, and R. C. Lieberman, Rev. Geoph. 6, 491 (1968), and references therein.

31. C. F. Cline, H. L. Dunegan, and G. W. EJenderson, J. Appl. Phys. 38, 1944 (1967).

32. G. G. Bentle, J. Am. Ceram. Soc. 49, 125 (1966).

33. W. Herrmann, J. Appl. Phys. 40, 2490 (1969); Sandia Laboratories Reports SC-DR-68-321 (1968); SC-RR-66-2678 (1967).

34. B. M. Butcher and C. H. Karns, J. Appl. Phys. 40, 2967 (1969); Sandia Laboratories Report SC-RR-67-3040 (1968).

35. R. G. McQueen, J. N. Fritz, and S. P. Marsh, J. Geoph. Res, 68, 2319 (1963).

36. R. G. McQueen, S. P. Marsh, and J. N. Fritz, J. Geoph. Res. 72, 4999 (1967).

37. R. K. Linde and D. N. Schmidt, J. Appl. Phys. 37, 3259 (1966).

38. P. C. Lysne and W. J. Halpin, J. Appl. Phys. 39, 5488 (1968).

39. R. R. Buade, J. Appl, Phys. 39, 5693 (1968); 느, 3781 (1969). 